BMJ

Paediatrics

Open

\section{Impact of health behaviours and deprivation on well-being in a national sample of English young people}

To cite: Gireesh A, Das S, Viner RM. Impact of health behaviours and deprivation on well-being in a national sample of English young people. BMJ Paediatrics Open 2018;2:e000335. doi:10.1136/ bmjpo-2018-000335

- Additional material is published online only. To view please visit the journal online (http://dx.doi.org/10.1136/ bmjpo-2018-000335)

Preliminary findings of this paper were presented at the Adolescent Lives and Wellbeing 2017 Conference organised by University College London.

Received 14 June 2018 Revised 16 August 2018 Accepted 23 August 2018

\section{Check for updates}

C) Author(s) (or their employer(s)) 2018. Re-use permitted under CC BY. Published by BMJ.

${ }^{1}$ Population, Policy and Practice Programme, UCL Great Ormond Street Institute of Child Health, London, UK

${ }^{2}$ MRC Unit for Lifelong Health and Ageing at UCL, UCL Institute of Cardiovascular Science, London, UK

Correspondence to Mrs Aswathikutty Gireesh; a. aswathikutty-gireesh@ucl.ac.uk

\section{ABSTRACT}

Objective To determine the modifiable factors influencing well-being in boys and girls by accounting for deprivation, ethnicity and clustering within local authorities.

Methods We used data from a very large nationally representative survey, the What About Youth study involving 120115 adolescents aged 15 years. Our outcome measure of mental well-being was the Warwick-Edinburgh Mental Wellbeing Scale (WEMWBS). Potential explanatory factors included substance abuse, screen time, eating habits, reading, bullying, sleeping pattern, physical activity and area-level deprivation. We ran unadjusted and adjusted multilevel models for each explanatory factor, after adjusting for ethnicity, deprivation and including a random effect for the local authority.

Results Boys had a higher overall mean WEMWBS score than girls $(p<0.0001)$. In the adjusted model, each of multiple risk behaviours, eating habits, sleep, bullying, physical activity, screen-time and reading were independently associated with mental well-being in both boy and girls ( $p<0.0001$ for both). Sleep and eating behaviours had a stronger association in both sexes than bullying, physical activity and screen time. Young people from black ethnic groups had significantly higher wellbeing in both sexes. Deprivation was not associated with well-being among boys but was among girls.

Conclusion The largest contributors to adolescent well-being appear to be sleep, eating behaviours and bullying when considered in a multivariable framework. While adolescents from black ethnic groups had higher overall well-being scores, area deprivation did not affect male well-being but had a small effect on female wellbeing. Future longitudinal studies and health policies need to consider a range of behavioural factors to drive improvements in adolescent well-being.

\section{INTRODUCTION}

There are growing concerns about the wellbeing of young people in modern societies, particularly in the UK where there is evidence that young people's well-being is lower than in many comparable developed countries. ${ }^{12}$

Well-being is defined as 'the state of being comfortable, healthy or happy'. ${ }^{3}$ From a holistic perspective, well-being incorporates different dimensions of adolescent lives including social relationships and individual functioning. ${ }^{4}$ However, the determinants of

\section{What is already known on this topic?}

Young people's well-being may be affected by multiple individual and contextual factors.

Key determinants of adolescent well-being remain unclear.

Few studies have examined a wide range of potential determinants while adjusting for area-level deprivation.

\section{What this study hopes to add?}

Findings support current policy foci on bullying, physical activity and screen-time as correlates of well-being among young people.

- Sleep and eating behaviours may also be important policy targets for promoting adolescent well-being.

- A coherent policy framework to promote adolescent well-being needs to be multifaceted and consider a range of health factors in young people's lives.

adolescent well-being is a relatively understudied area in comparison with the large literature on factors associated with mental health problems, as well-being concept has only been on greater focus over the past two decades. $^{56}$

A wide range of factors have been shown to be related to adolescent well-being, including a range of cognitive and relational factors such as bullying, ${ }^{7}$ family structure and relationships, ${ }^{8}$ peer support ${ }^{9}$ and school connectedness. ${ }^{10}$ Other behaviours also influence well-being, including substance use (alcohol, drugs and smoking habits), ${ }^{1-13}$ fruit and vegetable consumption, ${ }^{14}$ breakfast consumption, $^{15}$ physical activity, ${ }^{16}$ sleep duration, ${ }^{17}$ sedentary behaviour ${ }^{718}$ and leisure time activities. ${ }^{19}$ However, published studies use a wide range of well-being measures, resulting in conflicting findings. ${ }^{2021}$ Furthermore, studies have largely focused on single risk factors and not explored how factors including behavioural factors interact to influence wellbeing. Additionally, given that many such 
Table 1 Descriptive statistics for well-being scores and explanatory variables under study, by gender

\begin{tabular}{|c|c|c|c|c|c|c|}
\hline & \multirow{2}{*}{$\begin{array}{l}\text { Total } \\
\mathbf{N}\end{array}$} & \multicolumn{2}{|l|}{ Boys } & \multicolumn{2}{|l|}{ Girls } & \multirow[b]{2}{*}{$P$ values } \\
\hline & & $\mathbf{N}$ & Mean (SD)/\% & $\mathbf{N}$ & Mean (SD)/\% & \\
\hline Full sample (N \%) & 120115 & 57153 & $47.58 \%$ & 62962 & $52.42 \%$ & \\
\hline WEMWBS scores & 117842 & 56352 & $47.82 \%$ & 61490 & $52.18 \%$ & $<0.0001$ \\
\hline Mean (SD) & & & $50(8.60)$ & & $45(9.66)$ & \\
\hline Substance use ${ }^{*}$ & 71133 & 32516 & $45.71 \%$ & 38617 & $54.29 \%$ & $<0.0001$ \\
\hline None & & 17133 & 52.69 & 19932 & 51.61 & \\
\hline One & & 10783 & 33.16 & 12150 & 31.46 & \\
\hline Two & & 3010 & 9.26 & 3785 & 9.8 & \\
\hline Three & & 1590 & 4.89 & 2750 & 7.12 & \\
\hline Unhealthy eating habits $†$ & 115918 & 55289 & $47.70 \%$ & 60629 & $52.30 \%$ & $<0.0001$ \\
\hline None & & 12081 & 21.85 & 11951 & 19.71 & \\
\hline One & & 20287 & 36.69 & 20389 & 33.63 & \\
\hline Two & & 16373 & 29.61 & 19064 & 31.44 & \\
\hline Three & & 6548 & 11.84 & 9225 & 15.22 & \\
\hline Sleeping hours (>8hours) & 117516 & 56,207 & $47.83 \%$ & 61307 & $52.17 \%$ & $<0.0001$ \\
\hline Not in the past 7 days & & 3676 & 6.54 & 6922 & 11.29 & \\
\hline Some days & & 11051 & 19.66 & 16051 & 26.18 & \\
\hline Most days & & 20,121 & 35.8 & 20928 & 34.14 & \\
\hline Everyday & & 21,361 & 38 & 17406 & 28.39 & \\
\hline Bullying & 117744 & 56309 & $47.82 \%$ & 61435 & $52.18 \%$ & $<0.0001$ \\
\hline No & & 45959 & 81.62 & 45094 & 73.40 & \\
\hline yes & & 10350 & 18.38 & 16341 & 26.60 & \\
\hline Physical activity & 118450 & 56674 & 47.85 & 61776 & 52.15 & $<0.0001$ \\
\hline Physically active & & 48172 & 85 & 44348 & 71.79 & \\
\hline Inactive & & 8502 & 15 & 17428 & 28.21 & \\
\hline Screen time & 118845 & 56892 & 47.87 & 61943 & $52.13 \%$ & $<0.0001$ \\
\hline About 2 hours/day & & 3609 & 6.34 & 3469 & 5.6 & \\
\hline$\leq 1$ hours/day & & 912 & 1.6 & 929 & 1.5 & \\
\hline About 3-4 hours/day & & 18621 & 32.73 & 17311 & 27.95 & \\
\hline About 5-6hours/day & & 17198 & 30.23 & 17850 & 28.82 & \\
\hline$\geq 7$ hours/day & & 16559 & 29.1 & 22387 & 36.14 & \\
\hline Reading & 118140 & 56513 & 47.84 & 61627 & 52.16 & $<0.0001$ \\
\hline None & & 14278 & 25.26 & 9875 & 16.02 & \\
\hline About Half an hour/day & & 17572 & 31.09 & 15363 & 24.93 & \\
\hline About 1 hour/day & & 12505 & 22.13 & 13442 & 21.81 & \\
\hline$\geq 2$ hours/day & & 12158 & 21.51 & 22947 & 37.24 & \\
\hline
\end{tabular}

Figures in bold refer to full sample distribution, the proportion of males and females in the study.

${ }^{*}$ Risk behaviours include smoking, drinking and cannabis use.

†Unhealthy eating habits include skipping breakfast, not having five portions of fruits and vegetables and consumption of takeaway food.

WEMWBS, Warwick-Edinburgh Mental Wellbeing score.

behaviours are strongly socially patterned, studies have thus far paid little attention to confounding by socioeconomic position and issues relating to the clustering of behaviours and well-being within localities.

Policy initiatives to improve well-being among young people have largely focused on cognitive and psychological factors related to resilience to adversity, and have paid little attention to the contribution of non-psychological modifiable factors, such as other lifestyle behaviours.
Understanding the potential contribution of modifiable behavioural factors to adolescent well-being may inform different strategies to improve young people's well-being.

We used a very large recent nationally representative and population-based survey of English adolescents aged 15 years to examine the contribution of individual-level modifiable behaviours to well-being, including potentially protective (sleep, reading and physical activity) and risk behaviours (substance use, unhealthy eating habits 
Table 2 Univariate analysis between well-being and explanatory variables, by gender

\begin{tabular}{llll} 
Modelt & & \\
\hline Boys & $95 \%$ Cl & Girls & \\
\hline B & $95 \% \mathrm{Cl}$
\end{tabular}

\begin{tabular}{|c|c|c|c|c|}
\hline \multicolumn{5}{|l|}{ Substance use } \\
\hline None & Reference & & Reference & \\
\hline One & $-0.34^{*}$ & $(-0.56$ to -0.13$)$ & $-1.48^{* *}$ & $(-1.70$ to -1.27$)$ \\
\hline Three & $-3.56^{\star \star}$ & $(-4.16$ to -2.95$)$ & $-5.89^{\star \star}$ & $(-6.47$ to -5.30$)$ \\
\hline \multicolumn{5}{|l|}{ Unhealthy eating habits } \\
\hline Two & $-3.36^{\star \star}$ & $(-3.60$ to -3.12$)$ & $-4.85^{\star \star}$ & $(-5.13$ to -4.58$)$ \\
\hline Three & $-5.00^{\star \star}$ & $(-5.39$ to -4.61$)$ & $-6.49^{\star \star}$ & $(-6.83$ to -6.14$)$ \\
\hline \multicolumn{5}{|l|}{ Sleeping hours (>8 hours) } \\
\hline Not in the past 7 days & Reference & & Reference & \\
\hline \multicolumn{5}{|l|}{ Bullying } \\
\hline No & Reference & & Reference & \\
\hline Yes & $-4.70^{\star \star}$ & $(-3.59$ to -3.31$)$ & $-5.84^{\star \star}$ & $(-5.25$ to -4.90$)$ \\
\hline \multicolumn{5}{|l|}{ Physical activity } \\
\hline Physically active & Reference & & Reference & \\
\hline Inactive & $-3.85^{\star \star}$ & $(-4.11$ to -3.61$)$ & $-2.77^{\star \star}$ & $(-3.04$ to -2.51$)$ \\
\hline \multicolumn{5}{|l|}{ Screen time } \\
\hline About 2 hours/day & Reference & & Reference & \\
\hline$\leq 1$ hours/day & 0.07 & $(-0.59$ to 0.73$)$ & 0.08 & $(-0.69$ to 0.85$)$ \\
\hline About 1 hour/day & $2.25^{\star \star}$ & (2.06 to 2.44 ) & $2.54^{\star \star}$ & (2.26 to 2.82 ) \\
\hline$\geq 2$ hours/day & $2.27^{\star \star \star}$ & (2.01 to 2.52 ) & $2.35^{\star *}$ & (2.05 to 2.66$)$ \\
\hline \multicolumn{5}{|l|}{ IMD scores } \\
\hline High deprivation & Reference & & Reference & \\
\hline Average deprivation & $0.57^{\star \star}$ & (0.31 to 0.81$)$ & $0.35^{\star \star}$ & (0.10 to 0.590 \\
\hline Least deprivation & $1.05^{\star \star}$ & (0.87 to 1.21$)$ & $1.16^{\star \star}$ & (0.92 to 1.40$)$ \\
\hline \multicolumn{5}{|l|}{ Ethnicity } \\
\hline White & Reference & & Reference & \\
\hline Mixed & 0.18 & $(-0.29$ to 0.65$)$ & $-0.44^{\star}$ & $(-0.82$ to -0.06$)$ \\
\hline Asian & $-0.54^{*}$ & $(-0.85$ to -0.23$)$ & $0.98^{\star \star}$ & (0.59 to 1.38$)$ \\
\hline Black & $0.91^{* \star}$ & (0.42 to 1.39$)$ & $1.10^{\star \star}$ & (0.67 to 1.52$)$ \\
\hline Other & $-0.45^{*}$ & $(-0.84$ to -0.04$)$ & 0.30 & $(-0.09$ to 0.70$)$ \\
\hline
\end{tabular}

${ }^{*} \mathrm{P}<0.05 ;{ }^{\star \star} \mathrm{P}<0.001$.

†Unadjusted model taking into account clustering at local authority level, multilevel models fitted with weighted design weights, quadratic function added to reading.

IMD, Index of Multiple Deprivation. 
and excessive screen time). Our objective was to identify modifiable behavioural factors for mental well-being in boys and girls using an adolescent-specific measure and accounting for deprivation, ethnicity and clustering within local authorities (LAs).

\section{METHODS}

\section{Study design and sample}

The What About Youth study is a large-scale youth-oriented survey funded by the Department of Health in England and carried out by NHS Digital in $2014 .^{22}$ The primary aim of the survey was to collect robust LA-level data on youth health behaviours and general health to improve their health outcomes. Study participants were those who turned 15 years old in the academic year 2013/2014. A random sampling methodology was employed to draw 298080 participants from the National Pupil Database. The sample size was calculated to attain 1000 young people in each of 152 LAs in England; two LAs were merged with their nearest neighbours due to small size.

The achieved sample was 120115 individuals, of whom $16 \%$ responded online and $84 \%$ via postal means (2835 opted out). The response rates differed by gender, with adjusted response rates of $35 \%$ in boys and $49 \%$ in girls, and by deprivation, ethnicity and LA. Non-response weights using these factors were calculated to provide alignment between the achieved and target samples. ${ }^{22}$ We obtained a fully anonymised cohort data electronically from the UK Data Service website. ${ }^{22}$

\section{Outcome variable}

Mental well-being was measured using the Warwick-Edinburgh Mental Wellbeing Scale, ${ }^{23}$ a population-level well-being measure. It is validated to use in adolescents aged 13 years or more and focus primarily on the positive aspects of mental well-being (internal consistency, $\alpha=0.90$ ). Participants indicate how often they feel like each of the 14 items using a 5-point scale that ranges from 5 'all the time' to 1 'none of the time'. ${ }^{24}$ Total scores ranged from 14 to 70 and were calculated by summing each participant's responses. The potential explanatory behavioural variables were identified from the literature review of previous publication. A detailed description of each variable is given in supplementary appendix A.

A composite variable for risk behaviour index for substance use was constructed by the summation of three dichotomous risk behaviour variables: (a) smoking: if currently smokes, (b) drinking alcohol: if drinks once a month or more frequently, (c) cannabis use: if ever tried cannabis. Based on the number of risk behaviours, we categorised it from 'none' to 'three'. Similarly, composite unhealthy eating habit index was derived from (a) skipping breakfast: if avoided breakfast in last 7 days, (b) poor diet: if consumed less than five portions of fruits and vegetables a day, (c) takeaway food: if consumed takeaway food in past 7 days. Based on a combination of unhealthy behaviours, the composite score was categorised into $0=$ none, $1=$ only one, $2=$ any two and $3=$ all three . Physical active for $60+$ min for at least 5 days were classified as 'physically active' and the rest 'physically inactive.' This threshold was defined in line with government recommendations, ${ }^{25}{ }^{26}$ except for the intensity of exercise which was not available in the dataset. The selected threshold was taken at 5 days a week, as only $13 \%$ reported being physically active for 7 days a week. A digital screen time variable was computed based on reported weekend and weekday usage of television, internet, smartphone and computer games. Subjects were categorised into ' $\geq 7$ hours/day', 'about 5-6 hours/day', 'about 3-4 hours/ day', 'about 2 hours/day' and ' $\leq 1$ hours/day'. Time spent reading on weekends and weekdays had response options ranging from none to 7 hours per day. Based on the distribution of data, we recoded the variable as 'none', 'about half an hour/day', 'about 1 hour/day' and '2 hours / day'. The frequency of 8 hours sleep in the last 7 days was coded as 'every day', 'most days', 'some days' and 'not in the past 7 days'. Bullying was measured with Olweus Bully/Victim Questionnaire, a reliable 8-item scale used to assess the bullying victimisation. ${ }^{27}$ We combined responses to create one overall measure of bullying experience (yes/no). In line with a previous study, ${ }^{28}$ adolescents who were bullied more than 'two or three times a month' were categorised as bullying victims.

Ethnicity, deprivation and mode of questionnaire completion were selected as confounders in the relationship between well-being and potential explanatory variables as shown in previous studies. ${ }^{7}$ Ethnicity was self-identified by participants' and was an adaptation of the 2001 UK census categories, supplemented by questions on the national group. English Index of Multiple Deprivation (IMD) was used as a measure of relative deprivation for small areas. ${ }^{29}$ IMD scores were divided into three deprivation categories as defined by quintiles of the national distribution: 1 and 2 (high deprivation), 3 (average), 4 and 5 (low). Participants were allowed to choose between online or postal modes of questionnaire completion.

\section{Analyses}

We conducted unadjusted and adjusted multilevel regression, in Stata V.14. For well-being scores, the interaction between gender and health behaviours was statistically significant $(p<0.001)$ and therefore, analyses were stratified by gender. All variables were plotted to check the distribution and normality was checked with the Kolmogorov-Smirnov test. All estimates were weighted by representativeness of participants to compensate for the disproportionate selection of sample and non-response bias. Pearson $\chi^{2}$ tests were used to compare differences in the distribution of explanatory variables by gender. An unadjusted analysis was run to test the association between each independent variable (substance use, unhealthy eating habits, screen time, reading, bullying, physical activity and sleeping hours) and the outcome adolescent well-being 
Table 3 Gender-stratified partially adjusted and fully adjusted multilevel modelling for well-being and explanatory variables

\begin{tabular}{|c|c|c|c|c|c|c|c|c|}
\hline \multirow[b]{3}{*}{ Variables } & \multicolumn{4}{|l|}{ Boys } & \multicolumn{4}{|l|}{ Girls } \\
\hline & \multicolumn{2}{|l|}{ Modelt } & \multicolumn{2}{|l|}{ Model¥ } & \multicolumn{2}{|l|}{ Model† } & \multicolumn{2}{|l|}{ Model¥ } \\
\hline & B & $95 \% \mathrm{Cl}$ & B & $95 \% \mathrm{Cl}$ & B & $95 \% \mathrm{Cl}$ & B & $95 \% \mathrm{Cl}$ \\
\hline \multicolumn{9}{|l|}{ Substance use } \\
\hline None & Reference & & Reference & & Reference & & Reference & \\
\hline One & $-0.40^{* \star}$ & $(-0.61$ to -0.18$)$ & -0.14 & $(-0.36$ to 0.08$]$ & $-1.51^{\star *}$ & $(-1.73$ to -1.30$)$ & $-0.77^{\star *}$ & $(-0.97$ to -0.57$)$ \\
\hline Two & $-2.16^{\star *}$ & $(-2.57$ to -1.75$)$ & $-1.05^{\star \star}$ & $(-1.42$ to -0.67$)$ & $-4.84^{\star *}$ & $(-5.22$ to -4.46$)$ & $-2.67^{\star *}$ & $(-3.01$ to -2.33$)$ \\
\hline Three & $-3.50^{\star *}$ & $(-4.11$ to -2.88$)$ & $-1.63^{\star \star}$ & ( -2.16 to -1.09$)$ & $-5.80^{\star *}$ & $(-6.36$ to -5.23$)$ & $-2.79^{\star *}$ & $(-3.35$ to -2.24$)$ \\
\hline \multicolumn{9}{|l|}{ Eating habits } \\
\hline None & Reference & & Reference & & Reference & & Reference & \\
\hline One & $-1.63^{\star \star}$ & $(-1.85$ to -1.41$)$ & $-0.89^{\star \star}$ & $(-1.18$ to -0.60$)$ & $-2.63^{\star \star}$ & $(-2.92$ to -2.34$)$ & $-1.37^{\star \star}$ & $(-1.69$ to -1.06$)$ \\
\hline Two & $-3.31^{* *}$ & $(-3.55$ to -3.08$)$ & $-1.84^{\star \star}$ & $(-2.14$ to -1.54$)$ & $-4.84^{\star *}$ & $(-5.12$ to -4.55$)$ & $-2.29^{\star *}$ & $(-2.64$ to -1.96$)$ \\
\hline Three & $-4.95^{\star \star}$ & $(-5.34$ to -4.56$)$ & $-2.44^{\star \star}$ & $(-2.82$ to -2.06$)$ & $-6.46^{\star *}$ & $(-6.79$ to -6.10$)$ & $-2.61^{\star *}$ & $(-3.04$ to -2.18$)$ \\
\hline \multicolumn{9}{|l|}{$\begin{array}{l}\text { Sleeping hours } \\
\text { (>8 hours) }\end{array}$} \\
\hline $\begin{array}{l}\text { Not in the past } \\
7 \text { days }\end{array}$ & Reference & & Reference & & Reference & & Reference & \\
\hline Some days & $2.98^{\star \star}$ & (2.50 to 3.45$]$ & $2.69^{\star *}$ & (2.10 to 3.28 ) & $4.69^{\star \star}$ & (4.36 to 5.01 ) & $3.71^{\star *}$ & (3.34 to 4.08 ) \\
\hline Most days & $5.55^{\star \star}$ & (5.11 to 5.99 ] & $4.30^{\star \star}$ & (3.78 to 4.82 ) & $8.35^{\star \star}$ & (8.01 to 8.69 ) & $6.64^{\star \star}$ & (6.28 to 7.00 ) \\
\hline Everyday & $7.45^{\star \star}$ & (7.03 to 7.86 ] & $5.79^{\star \star}$ & (5.29 to 6.28 ) & $10.65^{\star *}$ & (10.29 to ,11.01) & $8.16^{\star \star}$ & (7.72 to 8.60$)$ \\
\hline \multicolumn{9}{|l|}{ Bullying } \\
\hline No & Reference & & Reference & & Reference & & Reference & \\
\hline Yes & $-4.64^{\star \star}$ & ( -4.86 to -4.42$)$ & $-3.78^{\star \star}$ & $(-4.09$ to -3.48$)$ & $-5.77^{\star *}$ & $(-5.98$ to -5.56$)$ & $-4.01^{* *}$ & $(-4.23$ to -3.78$)$ \\
\hline \multicolumn{9}{|l|}{ Physical activity } \\
\hline $\begin{array}{l}\text { Physically } \\
\text { active }\end{array}$ & Reference & & Reference & & Reference & & Reference & \\
\hline Inactive & $-3.78^{* *}$ & $(-4.02$ to -3.55$)$ & $-2.63^{\star *}$ & $(-2.95$ to -2.30$)$ & $-2.77^{\star *}$ & $(-3.04$ to -2.50$)$ & $-1.70^{\star *}$ & $(-2.01$ to -1.39$)$ \\
\hline \multicolumn{9}{|l|}{ Screen time } \\
\hline $\begin{array}{l}\text { About } 2 \text { hours/ } \\
\text { day }\end{array}$ & Reference & & Reference & & Reference & & Reference & \\
\hline$\leq 1$ hours/day & 0.09 & $(-0.57$ to 0.75$]$ & 0.34 & $(-0.58$ to 1.26$)$ & 0.09 & $(-0.69$ to 0.87$)$ & -0.38 & $(-1.49$ to 0.72$)$ \\
\hline $\begin{array}{l}\text { About } \\
3-4 \text { hours/day }\end{array}$ & $-1.22^{\star *}$ & $(-1.60$ to -0.83$)$ & $-0.61^{*}$ & $(-0.99$ to -0.23$)$ & $-1.26^{\star *}$ & $(-1.70$ to -0.83$)$ & -0.54 & $(-1.14$ to 0.05$)$ \\
\hline $\begin{array}{l}\text { About } \\
5-6 \text { hours/day }\end{array}$ & $-2.15^{\star \star}$ & $\begin{array}{l}(-2.50 \text { to }- \\
1.81)\end{array}$ & $-0.82^{\star \star}$ & $(-1.27$ to -0.37$)$ & $-3.04^{\star *}$ & $(-3.49$ to -2.58$)$ & $-1.21^{\star *}$ & $(-1.75$ to,-0.67$)$ \\
\hline$\geq 7$ hours/day & $-3.67^{\star \star}$ & $(-4.06$ to -3.27$)$ & $-1.20^{\star \star}$ & $(-1.65$ to -0.75$)$ & $-5.32^{\star *}$ & $(-5.73$ to -4.90$)$ & $-1.81^{\star *}$ & $(-2.29$ to -1.33$)$ \\
\hline \multicolumn{9}{|l|}{ Reading } \\
\hline None & Reference & & Reference & & Reference & & Reference & \\
\hline $\begin{array}{l}\text { About Half an } \\
\text { hour/day }\end{array}$ & $1.59^{\star \star}$ & (1.38 to 1.80$)$ & $0.57^{\star \star}$ & (0.26 to 0.88$)$ & $2.13^{\star \star}$ & (1.84 to 2.42 ) & $0.56^{\star \star}$ & $(0.23$ to 0.90$)$ \\
\hline $\begin{array}{l}\text { About } 1 \text { hour/ } \\
\text { day }\end{array}$ & $2.24^{\star \star}$ & (2.04 to 2.43 ) & $1.04^{\star \star}$ & (0.79 to 1.29$)$ & $2.51^{\star *}$ & (2.24 to 2.78 ) & $0.60^{\star \star}$ & (0.26 to 0.93 ) \\
\hline$\geq 2$ hours/day & $2.28^{\star \star}$ & (2.05 to 2.54 ) & $0.90^{\star \star}$ & (0.55 to 1.25$)$ & $2.34^{\star *}$ & (2.03 to 2.64 ) & $0.33^{*}$ & (0.02 to 0.64$)$ \\
\hline \multicolumn{9}{|l|}{ IMD scores } \\
\hline $\begin{array}{l}\text { High } \\
\text { deprivation }\end{array}$ & - & - & Reference & & - & - & Reference & \\
\hline $\begin{array}{l}\text { Average } \\
\text { deprivation }\end{array}$ & - & - & -0.12 & $(-0.38$ to 0.14$)$ & - & - & 0.16 & $(-0.16$ to 0.49$)$ \\
\hline $\begin{array}{l}\text { Least } \\
\text { deprivation }\end{array}$ & - & - & 0.17 & $(-0.06$ to 0.40$)$ & - & - & $0.36^{*}$ & (0.06 to 0.66 ) \\
\hline \multicolumn{9}{|l|}{ Ethnicity } \\
\hline White & - & - & Reference & & - & - & Reference & \\
\hline Mixed & - & - & -0.06 & (0.81 to -0.59$)$ & - & - & 0.44 & $(-0.08$ to 0.96$)$ \\
\hline Asian & - & - & -0.09 & (0.81 to -0.84$)$ & - & - & 0.35 & $(-0.53$ to 1.23$)$ \\
\hline Black & - & - & $0.99^{*}$ & (0.01 to 0.25 ) & - & - & $1.75^{\star \star}$ & (1.20 to 2.31 ) \\
\hline
\end{tabular}


Table 3 Continued

\begin{tabular}{|c|c|c|c|c|c|c|c|c|}
\hline \multirow[b]{3}{*}{ Variables } & \multicolumn{4}{|c|}{ Boys } & \multicolumn{4}{|c|}{ Girls } \\
\hline & \multicolumn{2}{|c|}{ Model† } & \multicolumn{2}{|c|}{ Modelf } & \multicolumn{2}{|c|}{ Model† } & \multicolumn{2}{|c|}{ Model‡ } \\
\hline & B & $95 \% \mathrm{Cl}$ & B & $95 \% \mathrm{Cl}$ & B & $95 \% \mathrm{Cl}$ & B & $95 \% \mathrm{Cl}$ \\
\hline Other & - & - & -0.59 & (0.02 to -1.09$)$ & - & - & -0.19 & $(-0.88$ to 0.49$)$ \\
\hline \multicolumn{9}{|c|}{$\begin{array}{l}\text { Mode of } \\
\text { questionnaire } \\
\text { delivery }\end{array}$} \\
\hline Online & - & - & & & - & - & & \\
\hline paper & - & - & 0.24 & $(-0.03$ to 0.51$)$ & - & - & $1.26^{* \star}$ & (0.99 to 1.53 ) \\
\hline
\end{tabular}

Multilevel models fitted with weighted design weights, quadratic function added to reading.

${ }^{*} \mathrm{P}<0.05 ; \mathrm{P}<0.005$.

†Each predictor variable adjusted for ethnicity, mode of questionnaire delivery and IMD.

$\ddagger$ All variables mutually adjusted for each other.

IMD, Index of Multiple Deprivation.

(model 1). The analyses were repeated in a multivariable analysis where ethnicity, mode of questionnaire delivery and IMD were added as confounders between each risk factor and outcome (model 2). In model 3, all explanatory factors and covariates were included simultaneously to obtain associations between each variable and wellbeing scores after adjusting for confounders and other explanatory variables. LAs were treated as random effects in all models. Models were also tested for significant quadratic terms signifying curvilinear relationships; this was only significant for reading. The intraclass correlations coefficient, being the proportion of total variance attributable to differences at the LA level, was estimated using multilevel models for well-being with adjustment for IMD, ethnicity and mode of completion.

\section{RESULTS}

In total, 57153 boys $(47.82 \%)$ and 62962 girls $(52.18 \%)$ participated in the study (table 1). Of these, boys had
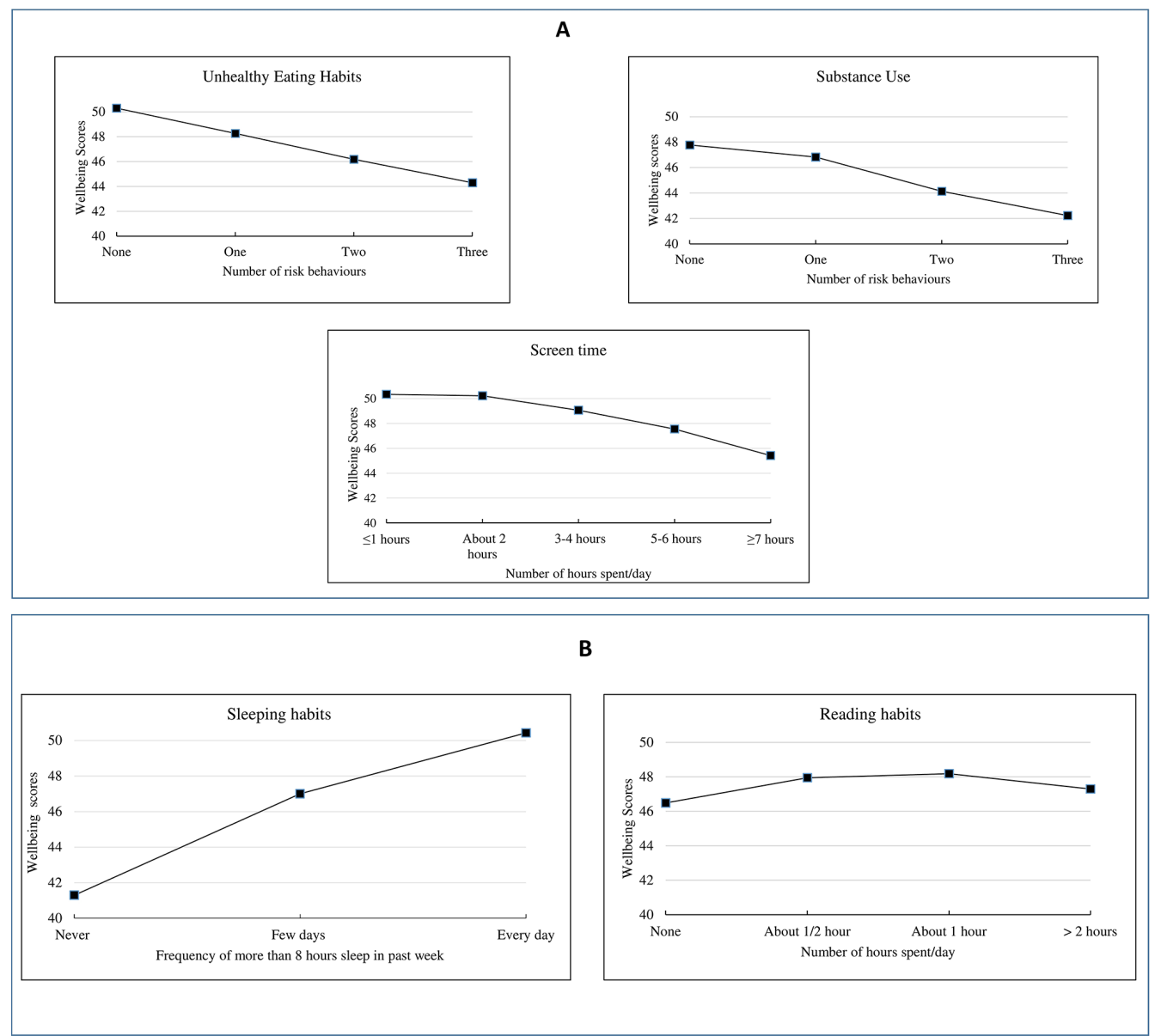

Figure 1 Relationship between well-being and health behaviours: (A) risk factors, (B) protective factors. 
higher average well-being score in comparison with girls. The intracluster correlation coefficient for the well-being score was 0.032 for girls and 0.024 for boys in the adjusted model, suggesting that variance in adolescent well-being is small at LA level.

Table 1 shows that there were significant differences in the distribution of potential explanatory variables between boys and girls. Girls had higher risk factors such as substance use, unhealthy eating habits, screen time and reported more bullying than boys. Protective variables such as sleeping hours (more than 8 hours) and reading were also significantly higher in girls than in boys.

All explanatory variables and IMD were significantly associated with well-being in both sexes (table 2). Wellbeing in both sexes decreased with the use of substance use, unhealthy eating habits, bullying, physical activity and longer screen time in both sexes. Protective factors, such as, sleeping more than 8 hours and reading more than 2 hours were associated with higher well-being in both sexes.

In the multivariable models adjusted for covariates (table 3), poorer well-being was associated with multiple substances use and multiple unhealthy eating habits in a dose-dependent fashion. Being physically inactive, longer screen time and experiencing bullying were both associated with decrements in well-being in both sexes, with the association being stronger in girls than in boys.

Higher well-being was associated with the number of days young people achieved more than 8 hours of sleep, again in a dose-dependent fashion. Habitual reading most days was associated with higher well-being although there was no evidence of a dose-response above $30 \mathrm{~min}$ per day in the fully adjusted model (figure 1). Adolescents from black ethnic groups had higher well-being scores overall. Area deprivation did not affect male wellbeing but had a small effect on female well-being.

\section{DISCUSSION}

This study broadens our understanding of risk and protective factors associated with well-being in adolescence, using a very large nationally representative survey to examine a wide spectrum of behavioural and psychosocial factors relating to youth well-being and taking into account deprivation and clustering at LA level. The study shows that young people who reported lower levels of well-being were more likely to have engaged in multiple unhealthy eating habits and substance use, be victims of bullying, have exercised insufficiently, have exceeded recommended screen time use. These findings were robust to mutual adjustment for all variables and for deprivation, ethnicity and mode of questionnaire delivery. A dose-response pattern was also observed between well-being and health behaviours such as substance use, unhealthy eating habits and sleeping pattern. A decrease in the number of risk behaviours and an increase in the number of days slept for more than 8 hours, corresponded with an increase in average levels of well-being. The impact of deprivation on well-being was surprisingly small, as was LA locality variance, suggesting that variance in well-being lies largely in behavioural and psychological factors.

Since different studies have used different variables to define various aspects of well-being in the analyses, comparison with other studies is difficult. We found boys reported higher mean well-being than girls, consistent with national reports for England, ${ }^{30} 31$ but in contrast to findings from recent Health Survey England 2015, where only slight gender variations were observed. ${ }^{32}$ The proportions reporting each of the behaviours were broadly similar to those found in other recent national surveys. ${ }^{31} 33$ Girls reported higher levels of risky health behaviours including current smoking, alcohol consumption, bullying and lower levels of physical activity. On the other hand, boys were more likely to report higher levels of physical activity, and these were consistent with findings from the Health Behaviour in School-aged Children England. ${ }^{33}$

These findings corroborate with two previous studies where happiness as a marker of well-being was found to be positively associated with multiple health protective behaviours (sports participation and healthier eating) and negatively associated with multiple risk behaviours (smoking, alcohol use and heavy screen use) in adolescents. ${ }^{35} 36$ Our finding that substance use was associated with lower well-being is similar to that seen in other studies, as were our findings for being bullied. ${ }^{7}$ The association of sleep duration and reading with well-being in young people has been little studied. Leisure time and adequate sleep have been identified as being associated with well-being, ${ }^{17} 19$ however ours is the first to examine these alongside other behavioural and psychological factors.

We found an association between deprivation and lower well-being, although in contrast to previous studies ${ }^{37}$ the association was small, and we found no association in boys. This may reflect the lack of adjustment for multiple behaviours, ethnicity and area effects in other studies. Our finding suggests that much of what has previously been understood as unhealthy behaviours themselves associated with deprivation may mediate deprivation effects. We found that young people from black ethnic groups reported significantly higher well-being in both sexes, consistent with previous UK findings. ${ }^{38}$ However, the reasons for this remain unclear and require further study. We found this association to be robust to adjustment for deprivation and all significant behavioural and psychological factors, suggesting this likely relates to factors not measured in our study.

We used a large, nationally representative sample of ethnically and socioeconomically diverse adolescents. Prior studies have examined very few health behaviours and relied on proxy measures of well-being rather than on population-level well-being measures that tap into both feelings and psychological flourishing. In our study, associations between well-being and behavioural factors 
were examined within a multivariable and multilevel framework, using a validated well-being scale with robust psychometric properties.

Our findings are subject to a number of limitations. Our data were cross-sectional and thus the direction of causality is unclear for the behavioural variables. Participant responses could be influenced by social desirability, and those with poor well-being may be inclined toward endorsing questions more than others, thus introducing bias. The direction of such biases is unclear, however, we note that girls (who had a higher response rate in the overall survey) reported higher levels of both more risky and protective behaviours than boys, potentially reflecting social desirability biases. All variables used were self-reported except for area-level deprivation. We have also repeated analysis excluding the outliers and that did not materially affect the findings. We used bullying victimisation as a proxy for psychological problems due to the lack of more appropriate variables in the dataset; thus it is possible that some of the associations seen here result from inadequate adjustment for psychological issues. We combined variables across domains into composite variables. this may have introduced bias although the direction of bias is unclear.

\section{CONCLUSION}

Our findings suggest that promoting healthy sleep, reading and healthy eating behaviours may present important policy targets for enhancing adolescent well-being in addition to more accepted foci on physical activity, screen time and bullying. While there was an association between deprivation and well-being, the association was small. Future work is needed to examine these modifiable factors within a longitudinal causal framework.

Contributors $A G$ and $S D$ led the writing of the study and undertook the analyses. RV conceptualised the project, contributed to the ideas underlying the article, contributed to writing and revision of the article.

Funding This report is an independent research commissioned and funded by the National Institute for Health Research Policy Research Programme.

Disclaimer The views expressed in this publication are those of the author(s) and not necessarily those of the NHS, the National Institute for Health Research, the Department of Health or its arm's length bodies and other Government Departments.

Competing interests None declared.

Patient consent Not required.

Ethics approval The National Children's Bureau carried out a detailed ethical review of the original study, but it was not required for this secondary data analysis.

Provenance and peer review Not commissioned; externally peer reviewed.

Open access This is an open access article distributed in accordance with the Creative Commons Attribution 4.0 Unported (CC BY 4.0) license, which permits others to copy, redistribute, remix, transform and build upon this work for any purpose, provided the original work is properly cited, a link to the licence is given, and indication of whether changes were made. See: https://creativecommons.org/ licenses/by/4.0/.

\section{REFERENCES}

1. Patton GC, Sawyer SM, Santelli JS, et al. Our future: a Lancet commission on adolescent health and wellbeing. Lancet 2016;387:2423-78.

2. RCPCH. State of child health report royal college of paediatrics and child health; 2017. http://www.thehealthwell.info/node/1062390 (accessed 6 Nov 2017).

3. Oxford University Press. Oxford Dictionary. Oxford: Oxford University Press, 2016.

4. Žukauskienė R, et al. Adolescence and Well-Being. In: Ben-Arieh A, Casas F, Frønes I, Handbook of Child Well-Being: Theories, Methods and Policies in Global Perspective. Dordrecht: Springer Netherlands, 2014:1713-38.

5. Das JK, Salam RA, Lassi ZS, et al. Interventions for adolescent mental health: an overview of systematic reviews. J Adolesc Health 2016;59:S49-S60 https://doi.org/.

6. Keyes CL. Promoting and protecting mental health as flourishing: a complementary strategy for improving national mental health. Am Psychol 2007;62:95-108.

7. Przybylski AK, Bowes L. Cyberbullying and adolescent well-being in England: a population-based cross-sectional study. Lancet Child Adolesc Health 2017;1:19-26.

8. Dinisman T, Andresen S, Montserrat C, et al. Family structure and family relationship from the child well-being perspective: Findings from comparative analysis. Child Youth Serv Rev 2017;80:105-15 https://doi.org/.

9. Raja SN, McGee R, Stanton WR. Perceived attachments to parents and peers and psychological well-being in adolescence. J Youth Adolesc 1992;21:471-85.

10. García Bacete FJ, Marande Perrin G, Schneider BH, et al. Effects of School on the Well-Being of Children and Adolescents. In: Ben-Arieh A, Casas F, Frønes I, eds. Handbook of Child Well-Being: Theories, Methods and Policies in Global Perspective. Dordrecht. Springer Netherlands, 2014:1251-305.

11. Taylor G, McNeill A, Girling A, et al. Change in mental health after smoking cessation: systematic review and meta-analysis. BMJ 2014;348:g1151.

12. Farmer $\mathrm{S}$, Hanratty $\mathrm{B}$. The relationship between subjective wellbeing, low income and substance use among schoolchildren in the north west of England: a cross-sectional study. J Public Health 2012;34:512-22.

13. Phillips-Howard PA, Bellis MA, Briant LB, et al. Wellbeing, alcohol use and sexual activity in young teenagers: findings from a crosssectional survey in school children in North West England. Subst Abuse Treat Prev Policy 2010;5:27.

14. Conner TS, Brookie KL, Carr AC, et al. Let them eat fruit! The effect of fruit and vegetable consumption on psychological wellbeing in young adults: A randomized controlled trial. PLoS One 2017;12:e0171206.

15. Lien $\mathrm{L}$. Is breakfast consumption related to mental distress and academic performance in adolescents? Public Health Nutr 2007;10:422-8.

16. Ussher $\mathrm{MH}$, Owen CG, Cook DG, et al. The relationship between physical activity, sedentary behaviour and psychological wellbeing among adolescents. Soc Psychiatry Psychiatr Epidemiol 2007;42:851-6.

17. Fuligni AJ, Hardway C. Daily variation in adolescents' sleep, activities, and psychological Well-Being. Journal of Research on Adolescence 2006;16:353-78.

18. Hamer M, Yates T, Sherar LB, et al. Association of after school sedentary behaviour in adolescence with mental wellbeing in adulthood. Prev Med 2016;87:6-10 https://doi.org/.

19. Trainor S, Delfabbro P, Anderson S, et al. Leisure activities and adolescent psychological well-being. J Adolesc 2010;33:173-86.

20. Pollard EL, Lee PD. Child well-being: a systematic review of the literature. Soc Indic Res 2003;61:59-78.

21. Rose T, Joe S, Williams A, et al. Measuring mental wellbeing among adolescents: a systematic review of instruments. J Child Fam Stud 2017;26:2349-62.

22. Health and Social Care Information Centre. What About YOUth? Survey. England: UK Data Service, 2016.

23. Tennant R, Hiller L, Fishwick R, et al. The Warwick-Edinburgh Mental Well-being Scale (WEMWBS): development and UK validation. Health Qual Life Outcomes 2007;5:63.

24. Taggart F, Stewart-Brown S, Parkinson J. Warwick-Edinburgh Menta Well-being Scale (WEMWBS) Scotland: NHS Health Scotland; 2015. http://www.healthscotland.com/uploads/documents/26787WEMWBS\%20User\%20Guide\%20Version\%202\%20May\%202015. pdf (accessed 19 Oct 2017).

25. Morgan K, Hallingberg $\mathrm{B}$, Littlecott $\mathrm{H}$, et al. Predictors of physical activity and sedentary behaviours among 11-16 year olds: Multilevel 
analysis of the 2013 Health Behaviour in School-aged Children (HBSC) study in Wales. BMC Public Health 2016;16:569.

26. Booth ML, Okely AD, Chey T, et al. The reliability and validity of the physical activity questions in the WHO health behaviour in schoolchildren (HBSC) survey: a population study. Br J Sports Med 2001;35:263-7.

27. Olweus D. The Revised Olweus Bully/Victim Questionnaire: Research Center for Health Promotion (HEMIL Center: University of Bergen, 1996.

28. Cook CR, Williams KR, Guerra NG, et al. Predictors of bullying and victimization in childhood and adolescence: A meta-analytic investigation. School Psychology Quarterly 2010;25:65-83.

29. Department for Communities and Local Government. The English indices of deprivation London2015. https://www.gov.uk/government/ uploads/system/uploads/attachment data/file/465791/English Indices_of_Deprivation_2015_-_Statistical_Release.pdf.

30. Office of National Statistics. Measuring National Well-being: Insights into children's mental health and well-being. England, 2015.

31. Office of National Statistics. Young people's well-being england: office for National Statistics; 2017. https://www.ons.gov.uk/peop lepopulationandcommunity/wellbeing/articles/youngpeopleswellbein gandpersonalfinance/2017 (accessed 10 Nov 2017).
32. Fuller E, Morris S. Health Survey for England: London NHS Digital, 2015.

33. Currie C, Grieber R, Inchley J. Health Behaviour in School-Aged Children (HBSC) Study Protocol: Background, Methodology and Mandatory Items for the 2009/10 Survey. Edinburgh: CAHRU, 2010.

34. Brooks F, Magnusson J, Klemera E, et al. Health Behaviours of School-Aged Children (HBSC) 2013-2014 England2014. www. hbscengland.com.

35. Booker CL, Skew AJ, Sacker A, et al. Well-being in adolescencean association with health-related behaviors:findings from understanding society, the uk household longitudinal study. The Journal of Early Adolescence 2014;34:518-38.

36. Booker CL, Skew AJ, Kelly YJ, et al. Media use, sports participation, and well-being in adolescence: cross-sectional findings from the uk household longitudinal study. Am J Public Health 2015;105:173-9.

37. Currie C, Zanotti C, Morgan A, et al. Social determinants of health and well-being among young people. International report from the 2009/2010 survey Health Behavior in school-age children (HBSC) study. Denmark: WHO Regional Office for Europe, 2012:252.

38. Patalay P, Fitzsimons E. Correlates of mental illness and wellbeing in children: are they the same? results from the uk millennium cohort study. J Am Acad Child Adolesc Psychiatry 2016;55:771-83. 